\title{
Supply of alcohol to underage drinkers: Misperceptions of community norms
}

Sandra C. Jones, ${ }^{\mathrm{a}, 1}$ Kate L. Francis ${ }^{\mathrm{a}}$

a, Centre for Health and Social Research (CHaSR), Australian Catholic University, Melbourne, Victoria

\section{${ }^{1}$ Corresponding author:}

Sandra C Jones

Director, Centre for Health and Social Research (CHaSR)

Australian Catholic University

Level 5, 215 Spring St, Melbourne VIC 3000

T: +6139953 3709 F: +61396508725

E: Sandra.Jones@acu.edu.au

\section{Acknowledgements}

The first author is funded by an Australian Research Council Future Fellowship

(FT120100932). The authorthanks Kelly Andrewsfor project management, Dr Lynda

Berends for feedback on the draft manuscript, and the students, school and community members for participating in the research.

(C) 2015. This manuscript version is made available under the Elsevier user license http://www.elsevier.com/open-access/userlicense/1.0/ 


\title{
Supply of alcohol to underage drinkers: Misperceptions of community norms
}

\begin{abstract}
Rationale: Adult approval and acceptance of alcohol use is highly correlated with underage drinking. Social norms influence young people's decisions to drink alcohol. While there is a dearth of studies to date, it is likely that social norms also influence adults' decisions to provide adolescents with alcohol. Objective: The current study explored the (in)consistencies between own and perceptions of others' views of underage drinking and the provision of alcohol to underage drinkers. Methods: Computer assisted telephone survey of 1160 adults in two communities in New South Wales, Australia. Results: Parents and community members were generally opposed to underage drinking and supply of alcohol to adolescents. Females, older respondents, and those who were parents were significantly more likely to disapprove of both underage drinking and supply of alcohol.However, across all of the behaviours, parents and non-parents alike perceived general community attitudes to be more liberal than their own. Conclusion: There is a need for community-based interventions that target parental misperceptions about the prevalence of youth drinking and the acceptability of drinking and supply of alcohol within their local community.
\end{abstract}

Keywords: Alcohol; adolescents; parents; community; social norm; Australia 


\section{Introduction}

In Australia, 29\% of high school students (aged 12-17 years), including 59.3\% of 17-yearolds, report having consumed alcohol in the past 30 days(White \& Bariola, 2012). Adolescent drinking is associated with increased risk of short-term and long-term harms (Gilchristet al.,2012; Healey et al., 2014). Regular alcohol consumption or binge drinking during adolescence also predicts heavier alcohol consumption, alcohol dependence, and poor health outcomes in early and middle adulthood (Bonomoet al.,2004; Pitkänenet al.,2008).

\subsection{Parental (and secondary) supply}

Adult approval and acceptance of alcohol use is highly correlated with underage drinking behaviour(Foley et al.,2004). In 2011, 32.9\% of 12-17 year old drinkers reported that their last alcohol drink was provided to them by their parents (legal in all Australian jurisdictions), $22.8 \%$ by their friends, $21.3 \%$ by someone purchasing it for them, $8.0 \%$ by their sibling (White \& Bariola, 2012).

There are a range of factors associated with parental provision of alcohol to minor children, such as parent gender, socio-demographic status, own drinking, ethnicity, religion, education level and employment status(Jacksonet al., 2012; Smyth et al.,2010). There is also a substantial body of evidence that many parents believe that supplying their teenage child with alcohol is an effective method to teach socially responsible drinking, and that a controlled and supervised introduction to alcohol minimises the likelihood of children engaging in excessive consumption as an act of rebellion (Gilligan \& Kypri, 2012; Jackson et al., 2012; Robertset al.,2010). 
There is extensive evidence that young people's drinking is heavily influenced by perceived social norms (Brooks-Russell et al., 2014; Voogt et al., 2013). While far less researched, it is likely that social norms also influence the decisions made by parents and other adults in relation to the supply of alcohol to minors; that these norms may also be inaccurate; and that they may be in part the result of (incorrect) information provided to parents by adolescents themselves (Gilligan et al.,2012).

Perceived norms surrounding the drinking behaviours 'other parents' condone influence parental attitudes; a qualitative study found that perceived pressure from other parents was an important factor in allowing teenagers to drink (Gilligan \& Kypri, 2012). Similarly, a survey of 161 mothers found that $17 \%$ reported feeling pressured by others to allow their children to drink before the age of 18 [injunctive norm] and 37\% said they would teach their children about alcohol the same way their parents taught them [descriptive norm] (Roberts et al.,2010).

In relation to the supply of alcohol to minors by adults other than parents without parental consent (illegal in the majority of Australian jurisdictions), an evaluation of a communication campaign in New South Wales found that many respondents perceived the provision of alcohol to minors to be culturally and socially acceptable and felt that this was a more important consideration than the law (Jones et al.,2012).

\subsection{Study purpose and hypotheses}

Despite the substantial evidence that parents and other adults provide alcohol to children and adolescents, there is a dearth of research into adults' views, and their perceptions of community views, on the acceptability of this behaviour. The purpose of the current study was to explore adults' views and the (in)consistencies between their own and perceptions of 
others' views. We did not seek to compare perceived norms to actual behaviour given the increasing evidence that self-reports of parental alcohol provision are inaccurate (Jones 2015; Jones et al., 2015). As it has been suggested that alcohol-related norms are likely to exist in small networks, such as parents of children in a defined community, and that understanding these community-level norms is an important step in the development of interventions (Gilligan et al.,2012), data were collected from adults in two discrete regional communities.

Based on the limited literature on parents' and other adults' attitudes and perceived social norms regarding adolescent drinking and supply of alcohol, and extrapolating from the literature on adolescents' perceptions of social norms, we hypothesised that:

H1: respondentswill largely disapprove of underage drinking andparental supply of alcohol to underage drinkers, and more so of the supply of alcohol to underage drinkers by other adults.

$\mathrm{H} 2$ : respondentswill perceive that other adults are more approving of underage drinking, and of parents and non-parents providing alcohol to underage drinkers, than they are themselves.

\section{Study Methods}

The protocol for the studywas approved by the Human Research Ethics Committees of the University of Wollongong and the Australian Catholic University.

\subsection{Participants and recruitment}

Data were collected in two communities in New South Wales, Australia. Both are coastal locations on the Australian eastern seaboard thatare scenic tourist attractions. In both communities the main source of employment is retail, accommodation and food services, 
followed by health care. Community A has a population of approx. 20,000 and is $120 \mathrm{~km}$ from a large major city; Community B has a population of approx. 40,000, and is $200 \mathrm{~km}$ from a large major city. The population of $12-17 \mathrm{yr}$ olds is approx. $8 \%$ for both communities; and both have the same Accessibility/Remoteness Index of Australia (ARIA) classification and comparable socio-economic index (SEIFA) scores.

Two commercial providers were contracted to conduct computer-aided telephone interviews (CATI) in two communities in October 2013; with a target of 550 completed responses per community. The selection criteria were residents who had lived there for 6 months or longer and were aged 18 years or older. Quotas were established to ensure an approximately even number of male and female respondents, and approximately $50 \%$ with dependent children. The two providers utilised slightly different processes for selecting telephone numbers and interviewees.In Community A the sample base was the electronic White Pages, using a technique that starts with the population of numbers listed and adds new and unlisted numbers; with a computer program used to randomise the database and extract a sequential sample. In Community B, numbers to be called were drawn from a large database of validated Random Digit Dial (RDD) fixed line telephone numbers; with the downloaded numbers loaded in the CATI sample management system and randomised.

In Community A, 3360 valid numbers were called; 2,204 were not eligible or outside quotas, 546 refused, and 610 interviews were completed (53\% completion rate from eligible contacts, $18.2 \%$ of numbers called). In Community B, 4511 valid numbers were called; 1,998 were not eligible or outside quotas, 1,963 refused, and 550 interviews were completed (22\% completion rate from eligible contacts, $12.2 \%$ of numbers called). 
Overall there were 1160 respondents, with no differences between Community A and B with regard to parental status orchild(ren) age. A total of $22.4 \%$ (260) respondents had no children of any age; $25.7 \%$ (298) had one or more children aged zero to 11 years; $29.4 \%$ (341) one or more children aged 12 to 17 ; and $45.7 \%$ (530) one or more children aged 18 and over. In total, $33.2 \%$ (385) had children over the age of 18 only, $31.9 \%$ (370) children under 18 only, and $12.5 \%$ (145) children aged over and under 18 years at the time of the survey. There were $674(58.1 \%)$ female respondents; and respondent age was distributed across less than 40 years (22.4\%); $40-54$ years $(44.4 \%)$, and 55 years or more $(33.1 \%)$.

\subsection{Survey Instrument}

Respondents were asked to respond to a series of seven opinion statements (on a five-point scale from 'strongly agree' to 'strongly disagree') on their personal opinion as to the acceptability ofvarious behaviours. There was one statement in relation to adolescent drinking; three in relation to parental supply of alcohol; and three in relation to supply of alcohol by other adults. They were then asked to respond to the same series of statements in the context of their community of residence ("As far as you know, among adults in the [name] community is it acceptable or unacceptable for....").The rate of missing data was very low (0 to $1.3 \%$ ); therefore imputation was not used, and those cases with missing values were excluded.

\section{Findings}

Univariate analysis foundthat membersfrom community Atended to be more likely to approve two of the seven behaviourscompared to community B, but these differences were not significant after controlling for the demographic differences between the two communities. 
However, membersfrom community A were more likely to believe that others in the community disapproved of four out of seven behaviourscompared to community $\mathrm{B}$, and these differences remained after controlling for these demographic differences (see limitations section).

\subsection{Attitudes to underage drinking and supply of alcohol to teenagers}

Across the full sample, respondents were generally of the view that it was unacceptable for a 16-year-old to drink alcohol (mean 1.77 on a 5-point scale, where $1=$ definitely unacceptable and $5=$ definitely acceptable). They also felt it was unacceptable for parents to purchase alcohol for a 16-year-old, with greater levels of disapproval as the level of monitoring decreased; mean $=1.67$ for alcohol to drink at home, 1.36 for alcohol to drink away from home at a supervised party, and 1.09 for alcohol to drink away from home at an unsupervised party. As hypothesised, they were also more disapproving of someone other than a parent purchasing alcohol to drink at home $(1.24$ vs $1.67, t=17.59, p<0.001)$ or at a supervised $(1.19 \mathrm{vs} 1.36, t=9.38, p<0.001)$ or unsupervised party $(1.06 \mathrm{vs} 1.09, t=4.47, p<0.001)(\mathrm{H} 1$ supported).

Female respondents expressed a greater level of disapproval than male respondents across six of the statements (see Table 1); and younger respondents (those aged less than 40 years) were less likely to disapprove of each of the seven behaviours (see Table 2).

***INSERT TABLE 1 HERE***

Those who were the parent or guardian of any children were significantly more likely than non-parents to believe that all seven of the behaviours were unacceptable. As age was 
associated with differences in responses (Table1), an ANCOVA was performed using age as a covariate to confirm that the effect of parent status was independent of respondent age.The effect of parental status varied depending on the age of the children in the household. Those with children aged 12-17 years or aged 18 and over were significantly more likely to disapprove of six of the seven behaviours; whereas those with children aged zero to 11 years differed from non-parents in their attitudes towards only two of the behaviours (see Table 2).

***INSERT TABLE 2 HERE***

\subsection{Perceptions of "other people's" attitudes to underage drinking and supply of alcohol to} teenagers

Respondents were generally of the view that their community thought it was somewhat unacceptable for a 16-year-old to drink alcohol (mean 2.29 on a 5-point scale), for a parent to purchase alcohol for a 16-year-old to drink at home (2.36) or away from home at a supervised party (2.03); and unacceptable for a parent to purchase alcohol to drink away from home at an unsupervised party (1.60). As with their own attitudes, they perceived that the community was more disapproving of someone other than a parent purchasing alcohol to drink at home or at a supervised or unsupervised party (see Table 3).

\section{***INSERT TABLE 3HERE***}

Those with children $(n=900)$ did not differ from those without children $(n=260)$ in their perceptions of community attitudes towards six of the seven behaviours; however, nonparents were more likely to perceive that the community felt it was acceptable for a parent to purchase alcohol for a 16 year old to drink at home. Those with children under the age of 18 
were more likely than those without underage children to perceive that community attitudes were more liberal across all seven behaviours. As with their own attitudes, further analysis showed that this effect was stronger among those with children aged 12-17 years than those with children aged 0-11 years, particularly in relation to provision of alcohol by parents and by others for consumption at supervised and unsupervised parties.

Analysis by gender found only one significant difference; male respondents thought the community was less approving of a parent providing alcohol for a 16-year-old to consume at an unsupervised party. As with own attitudes, there was a strong correlation with the age of the respondent; for six of the seven variables, those aged 55 and over perceived community attitudes to be more conservative than.

It was clear that our respondents perceived general community attitudes to be more liberal than their own, across all seven attitudinal items measured (H2 supported); see the 'All' column in Tables 2 and 3 for self versus perceived community attitudes. This divergence was more pronounced among those who were parents (of any children) than those who were not. The divergence between own and perceived community attitudes was lowest among those with children aged 18 and over only (for six of the seven behaviours), higher among those with children under the age of 18 only (other than for 'someone other than a parent to purchase alcohol for a 16 year old to drink at an unsupervised party'); and substantially higher among those with children in both age groups.

\section{Discussion}

This study adds to the evidence base on parental attitudes towards alcohol supply by 
exploring difference in perceived acceptability across different scenarios. The majority of parent respondents reported that they did not think it was acceptable for a 16-year-old to consume alcohol, or for a parent to provide alcohol in any of the three scenarios. This finding is consistent with survey data from New Zealand (Kypriet al.,2007)that showed81\% of parents of 13-17 year olds disagreed that "It's okay for parents to give their teenager(s) one or two drinks to take to an unsupervised party". Further, the range in responses to the three different scenarios shows the nuances of the term 'supply' and that parents make clear differentiations between what they perceived to be 'lower risk' and 'higher risk' situations.

We found that females were less approving of underage drinking, parental supply, and supply by someone other than a parent than were males. This is consistent with previous research from New Zealand thatshowedmothers held more restrictive attitudes than did fathers(Kypri et al., 2007); survey data of Norwegian and Dutch parents also found that mothers were more supportive of parental control measures on underage drinking(van der Saret al., 2014). We also found that older respondents were less approving of underage drinking, parental supply, and supply by someone other than a parent than were younger respondents; consistent with findings from population surveys on attitudes to underage drinking and related policy measures in Australia and the US (FARE, 2013; Richter et al., 2004).

This study also adds to the evidence base by exploring differences in attitudes to underage supply between parents and other adults. Across all seven statements, those who were parents expressed less lenient views than those who were not parents. It is likely that parents would consider this provision within the context of the potential the harms of drinking for (their own) children, compared to non-parents who would likely be thinking about children in general. Consistent with this, those who were parents of children aged 12-17 years (the group 
for whom underage drinking is the most salient) reported far greater divergence between their own views and those they perceived to be held within their community. It is interesting to note that those who had children both under and over 18 years reported the highest level of divergence, perhaps due to having the combination of those entering and those leaving the higher risk age for alcohol initiation and (on both sides of the legal purchase age) high social pressure to consume alcohol.

The key contribution of the current study is the exploration of adults' perceptions of the views of other adults in their community regarding the provision of alcohol to minors. We found that both parents and non-parents perceived that the broader community held views that were more supportive of underage drinking, parental supply and secondary supply than were their own views. Given the substantial evidence that social norms influence the drinking behaviour of adolescents, and that parents perceive that parental supply is associated with the pressure to ensure that their children fit in with peers (Jones et al. 2015), there is a need for further research into the causes and effects of this gap between adults' views and their perception of community views.

\subsection{Limitations}

The two CATI providers utilised slightly different processes for identifying the sampling frame; with one using the electronic White Pages and adding new and unlisted numbers, and the other a large database of validated Random Digit Dial (RDD) fixed line telephone numbers. Households that do not have a fixed line telephone numbers (estimated to be about $20 \%$ of households) were excluded from the sample in both communities. This results in further bias of obtained samples toward older adults, as people aged 18-40 are more likely to 
live in a household without a fixed line telephone connection, although the survey providers attempted to address this by adhering to the pre-set age quotas. Underage drinking and the supply of alcohol to minors is a moralised issue and we cannot exclude the possibility that some of our respondents may have reported their own perceptions as more opposed to these behaviours than they are in reality in order to appear to be 'better' people.

After controlling for demographic differences, those from community A were slightly more likely to believe that others in the community disapproved of 16-year olds drinking, parents purchasing alcohol for a 16-year-old to drink at an unsupervised party, and someone other than a parent purchasing alcohol for consumption at a supervised or unsupervised party; however, none of these differences resulted in changes to the general findings (that is, the differences by demographics and parental status were robust across the two communities).

\subsection{Implications for practice}

Data collection occurred at a point in time where adolescent drinking rates in Australia were declining (AIHW, 2011), with rates of abstention among 14-17-year olds increasing from $32.9 \%$ in 2001 to $50.2 \%$ in 2010 (Livingston, 2014), but the high perceived acceptability of youth drinking among adults suggests that this encouraging trend has yet to be recognised by young people and their parents.

Our data supports the suggestion that there is a need for community-based interventions that target parental misperceptions about the prevalence of youth drinking and the acceptability of drinking and supply of alcohol among other parents and community members (Gilligan et al., 2012). The small but important differences between the two communities further demonstrate 
that - even within a single legal jurisdiction - there are differences in local beliefs and community norms that need to be considered in understanding, and influencing, the effect of social norms on behaviour at a community level. For example, given the evidence that close (injunctive and descriptive) norms have more influence on behaviour than distal norms, an effective social marketing intervention would collect information regarding local norms and utilisesuch information (rather than national or state figures)in community campaigns to reduce supply of alcohol to minors.

\section{References}

AIHW. (2011). 2010 National Drug Strategy Household Survey report. Drug statistics series Canberra: Australian Institute of Health and Welfare.

Bonomo, Y. A., Bowes, G., Coffey, C., Carlin, J. B., \& Patton, G. C. (2004). Teenage drinking and the onset of alcohol dependence: a cohort study over seven years. Addiction, 99(12), 1520-1528.

Brooks-Russell, A., Simons-Morton, B., Haynie, D., Farhat, T., \& Wang, J. (2014). Longitudinal relationship between drinking with peers, descriptive norms, and adolescent alcohol use. Prevention Science, 15(4), 497-505.

Foley, K. L., Altman, D., Durant, R. H., \& Wolfson, M. (2004). Adults' approval and adolescents' alcohol use. Journal of Adolescent Health, 35, 17-26.

FARE. (2013). Annual Alcohol Poll: Attitudes and Behaviours. Canberra: Foundation for Alcohol Research and Education.

Gilchrist, H., Smith, K. M., Magee, C., \& Jones, S. C. (2012). hangover and a one-night stand: alcohol and risky sexual behaviour among female students at an Australian University. Youth Studies Australia, 31(2), 35-43. 
Gilligan, C., \& Kypri, K. (2012). Parent attitudes, family dynamics and adolescent drinking: qualitative study of the Australian parenting guidelines for adolescent alcohol use. BMC Public Health, 12, 491.

Gilligan, C., Kypri, K., \& Lubman, D. (2012). Changing parental behaviours to reduce risky drinking among adolescents: current evident and future directions. Alcohol and Alcoholism, 47(3), 349-354.

Healey, C., Rahman, A., Faizal, M., \& Kinderman, P. (2014). Underage drinking in the UK: Changing trends, impact and interventions. A rapid evidence synthesis. International Journal of Drug Policy, 25, 124-132.

Jackson, C., Ennett, S. T., Dickinson, D. M., \& Bowling, J. M. (2012). Letting children sip: Understanding why parents allow alcohol use by elementary school-aged children. Archives of Pediatrics and Adolescent Medicine, 166, 1053-1057.

Jones, S. C., Robinson, L., Gilchrist, H., \& Barrie, L. (2012). Supply means supply - what does 'supply' mean? Consumer responses to a campaign targeting secondary supply of alcohol to teenagers. Paper presented at the Australia New Zealand Marketing Academy Conference, Edith Cowan University.

Jones, S. C., Magee, C.,\& Andrews, K. (2015) I think other parents might: Using a projective technique to explore parental supply of alcohol.Drug and Alcohol Review, 34, 531539.

Jones, S. C. (ePub ahead of print) Parental provision of alcohol: A TPB-framed review of the literature. Health Promotion International

Kypri, K., Dean, J. I., \& Stojanovski, E. (2007). Parent attitudes on the supply of alcohol to minors. Drug \& Alcohol Review, 26(1), 41-47.

Livingston, M. (2014). Trends in non-drinking among Australian adolescents. Addiction, 109(6), 922-929. 
Pitkänen, T., Kokko, K., Lyyra, A. L., \& Pulkkinen, L. (2008). A developmental approach to alcohol drinking behaviour in adulthood: a follow-up study from age 8 to age 42 . Addiction, 103(Suppl 1), 48-68.

Richter, L., Vaughan, R. D., \& Foster, S. E. (2004). Public attitudes about underage drinking policies: results from a national survey. Journal of Public Health Policy, 25(1), 58-77.

Roberts, R., Beckwith, M., \& Watts, D. (2010). Mothers' intentions to introduce their adolescent to alcohol use: does mothers' alcohol use effect intentions? Australian and New Zealand Journal of Public Health, 34, 281-287.

Smyth, B. P., Darker, C. D., Donnelly-Swift, E., Barry, J. M., \& Allwright, S. P. A. (2010). A telephone survey of parental attitudes and behaviours regarding teenage drinking. BMC Public Health, 10, 297.

van der Sar, R., Brouwers, E., van de Goor, I., Rise, J., \& Garretsen, H. (2014). Comparison between Dutch and Norwegian parents regarding their perceptions on parental measures to prevent substance use among adolescents. ddiction Research \& Theory, 22(1), 68-77.

Voogt, C. V., Larsen, H., Poelen, E. A. P., Kleinjan, M., \& Engels, R. C. M. E. (2013). Longitudinal associations between descriptive and injunctive norms of youngsters and heavy drinking and problem drinking in late adolescence. Journal of Substance Use, $18(4), 275-287$.

White, V., \& Bariola, E. (2012). Australian secondary school students' use of tobacco, alcohol, and over-thecounter and illicit substances in 2011. Melbourne: Centre for Behavioural Research in Cancer, The Cancer Council Victoria. 
Table 1.Community members' attitudesto underage drinking and the supply of alcohol to teenagers.

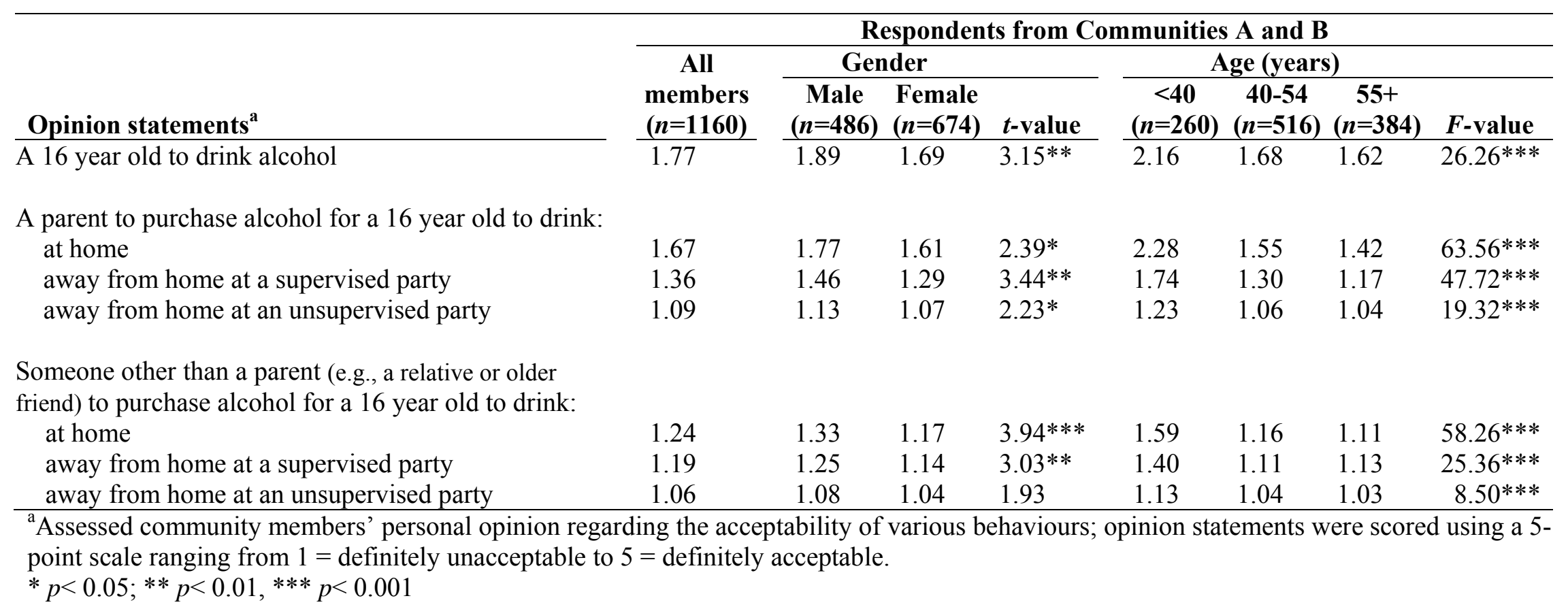


Table 2. Community members' attitudes to underage drinking and the supply of alcohol to teenagers by parental status and age of children.

\begin{tabular}{|c|c|c|c|c|c|c|c|c|c|}
\hline \multirow{2}{*}{ Opinion statements ${ }^{a}$} & \multicolumn{9}{|c|}{ Respondents from Communities $A$ and $B$} \\
\hline & \multirow{2}{*}{\begin{tabular}{l}
\multicolumn{1}{c}{$\begin{array}{c}\text { All } \\
\text { members }\end{array}$} \\
$(n=1160)$ \\
1.77
\end{tabular}} & \multicolumn{3}{|c|}{ Parental Status } & \multicolumn{5}{|c|}{$\begin{array}{c}\text { Age (years) of Children } \\
\end{array}$} \\
\hline A 16 year old to drink alcohol & & 1.67 & 2.11 & $38.43 * * *$ & 2.17 & 1.68 & 1.62 & 1.68 & $18.20 * * *$ \\
\hline \multicolumn{10}{|l|}{$\begin{array}{l}\text { A parent to purchase alcohol for a } 16 \text { year old to } \\
\text { drink: }\end{array}$} \\
\hline away from home at a supervised party & 1.36 & 1.27 & 1.66 & $54.43 * * *$ & 1.73 & 1.24 & 1.25 & 1.26 & $26.88 * * *$ \\
\hline away from home at an unsupervised party & 1.09 & 1.07 & 1.19 & $18.37 * * *$ & 1.21 & 1.01 & 1.06 & 1.08 & $10.24 * * *$ \\
\hline \multicolumn{10}{|l|}{$\begin{array}{l}\text { Someone other than a parent (e.g., a relative or } \\
\text { older friend) to purchase alcohol for a } 16 \text { year } \\
\text { old to drink: }\end{array}$} \\
\hline
\end{tabular}

${ }^{\text {a} A s s e s s e d ~ c o m m u n i t y ~ m e m b e r s ' ~ p e r s o n a l ~ o p i n i o n ~ r e g a r d i n g ~ t h e ~ a c c e p t a b i l i t y ~ o f ~ v a r i o u s ~ b e h a v i o u r s ; ~ o p i n i o n ~ s t a t e m e n t s ~ w e r e ~ s c o r e d ~ u s i n g ~ a ~ 5-~}$ point scale ranging from $1=$ definitely unacceptable to $5=$ definitely acceptable.

$* p<0.05 ; * * p<0.01, * * * p<0.001$ 
Table 3. Perceptions of community attitudes to underage drinking and the supply of alcohol to teenagers by parental status and age of children.

\begin{tabular}{|c|c|c|c|c|c|c|c|c|}
\hline \multirow[b]{3}{*}{ Opinion statements ${ }^{\text {a }}$} & \multicolumn{8}{|c|}{ Respondents from Communities A and B } \\
\hline & \multirow[b]{2}{*}{$\begin{array}{c}\text { All } \\
\text { members } \\
(n=1160)\end{array}$} & \multicolumn{3}{|c|}{ Parental Status } & \multicolumn{4}{|c|}{ Age (years) of Children } \\
\hline & & $\begin{array}{c}\text { Parent } \\
(n=885)\end{array}$ & $\begin{array}{c}\text { Non- } \\
\text { parent } \\
(n=260)\end{array}$ & t-value & $\begin{array}{c}\text { All } \\
\text { ages } \\
(n=144)\end{array}$ & $\begin{array}{c}>18 \\
\text { only } \\
(n=376)\end{array}$ & $\begin{array}{c}<18 \\
\text { only } \\
(n=365)\end{array}$ & $F$-value \\
\hline A 16 year old to drink alcohol & 2.29 & 2.28 & 2.32 & 0.50 & 2.42 & 2.13 & 2.38 & $6.84 * *$ \\
\hline \multicolumn{9}{|l|}{$\begin{array}{l}\text { A parent to purchase alcohol for a } 16 \text { year old } \\
\text { to drink: }\end{array}$} \\
\hline at home & 2.36 & 2.29 & 2.62 & $4.43 * * *$ & 2.58 & 2.08 & 2.39 & $15.28 * * *$ \\
\hline away from home at a supervised party & 2.03 & 2.02 & 2.07 & 0.64 & 2.31 & 1.85 & 2.08 & $11.75 * * *$ \\
\hline away from home at an unsupervised party & 1.60 & 1.62 & 1.54 & 1.44 & 1.86 & 1.54 & 1.61 & $6.91 * *$ \\
\hline \multicolumn{9}{|l|}{$\begin{array}{l}\text { Someone other than a parent (e.g., a relative or } \\
\text { older friend) to purchase alcohol for a } 16 \text { year } \\
\text { old to drink: }\end{array}$} \\
\hline at home & 1.76 & 1.74 & 1.82 & 1.32 & 1.99 & 1.61 & 1.77 & $9.18 * * *$ \\
\hline away from home at a supervised party & 1.73 & 1.74 & 1.70 & 0.52 & 2.00 & 1.62 & 1.75 & $8.48 * * *$ \\
\hline away from home at an unsupervised party & 1.49 & 1.51 & 1.42 & 1.47 & 1.75 & 1.46 & 1.46 & $6.85 * *$ \\
\hline
\end{tabular}

a'Assessed the respondent's perception of their community's opinion on the acceptability of various behaviours; opinion statements were scored using a 5 -point scale ranging from $1=$ definitely unacceptable to $5=$ definitely acceptable.

$* p<0.05 ; * * p<0.01, * * * p<0.001$ 